\title{
Numerical Investigation on Flow Field of the Projectile with Base Cavity
}

\author{
H.B. Lu \\ Nanjing Artillery Academy \\ Nanjing, China
}

\author{
S.Y. Tian \\ Nanjing Artillery Academy \\ Nanjing, China
}

\begin{abstract}
The paper focuses on the base cavity configuration of the projectile. The effect of the cavity length on the aerodynamic force of the projectile with base cavity is investigated numerically. With the supersonic flow field of the projectile simulating, the distributions of the flow field parameters and the aerodynamic drag was obtained. Numerical results show that with the larger length base cavity, the drag of the projectile is smaller.
\end{abstract}

Keywords-projectile with base cavity; supersonic; aerodynamic force; $C F D$

\section{INTRODUCTION}

There are three kinds of drag composing the aerodynamic drag of a projectile under a supersonic flow, base, wave and friction. The base drag is about 20 40 percent in the total. Reducing the base drag is an effective method to reduce the total flight drag of the projectile, which is helpful to its ballistic performance [1].

Base cavity configuration is an useful choice to reduce the base drag of projectiles. The correlative experiment results show that, under the same condition, the field of fire for projectile with base cavity is larger than the projectile without base cavity 3 5\% [2].

In this paper, the projectile with base cavity is investigated numerically. Remarkable aerodynamic drag reduction due to the base cavity in supersonic flow field is revealed by the simulation results. Furthermore, the influence of the cavity length is discussed.

\section{NUMERICAL METHOD}

A. Governing Equation and Grid

The axisymmetric Navier-Stokes equation is given by [3]

$\frac{\partial U}{\partial T}+\frac{\partial F(U)}{\partial x}+\frac{\partial G(U)}{\partial r}+\frac{1}{r} \cdot \frac{\partial H(U)}{\partial r}=\frac{1}{\operatorname{Re}} \cdot\left(\frac{\partial F_{v}(U)}{\partial x}+\frac{\partial G_{v}(U)}{\partial r}+\frac{1}{r} \cdot \frac{\partial H_{v}(U)}{\partial r}\right)$

where $\mathrm{U}$ is the conservation variable, $\mathrm{F}, \mathrm{G}$ and $\mathrm{H}$ are the inviscid terms, Fv, Gv and $\mathrm{Hv}$ are the viscous terms. The k- $\varepsilon$ turbulence model [4] was used.

The convective terms are approximated using the Van Leer splitting method and the central difference method is used for the viscous terms. The LU-SSOR scheme is used for the time integration.

The two-dimensional axisymmetric boundary-fitted grids for the projectile with base cavity (cavity length $10 \mathrm{~cm}$ ) are shown as Fig.1.

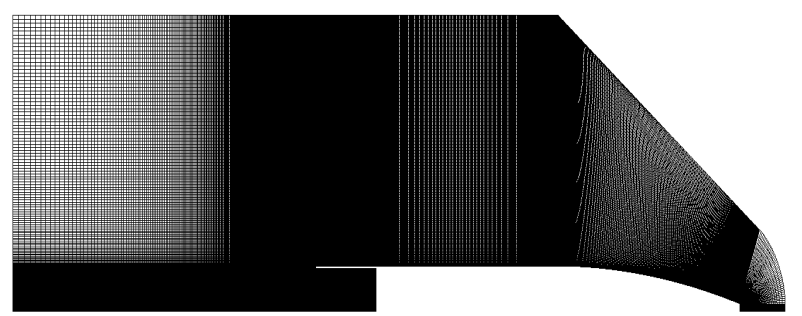

FIGURE I. GRID OF THE SIMULATION MODEL (CAVITY LENGTH 10CM)

\section{B. Boundary Condition and Numerical Assumption}

The boundary conditions are shown in Table 1 . The wall boundary condition is assumed to a no-slip and adiabatic one.

TABLE I. BOUNDARY CONDITIONS

\begin{tabular}{|l|l|l|}
\hline Free stream parameter & Unit & \multicolumn{1}{|c|}{ Value } \\
\hline Mach Number $(M a)$ & ---- & 1.97 \\
\hline Pressure $\left(p_{\infty}\right)$ & $\mathrm{Pa}$ & 101325 \\
\hline Temperature $\left(T_{\infty}\right)$ & $\mathrm{K}$ & 300 \\
\hline
\end{tabular}

\section{RESULTS AND DISCUSSION}

In order to discuss the influence of the length of the base cavity on the aerodynamic drag, projectile with different length $(6,12 \mathrm{~cm})$ base cavity is simulated.

\section{A. Flow Field}

The distributions of the Ma (streamlines) of the projectile with different cavity length are shown in Fig. 2. As shown in Fig.2, the classical bow shock is formed in front of the projectile. At the back of the projectiles, both with base cavity and without cavity, there is a recirculation region. The recirculation region maintain into the base cavity.

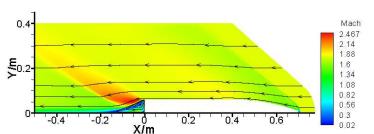

a. projectile without base cavity

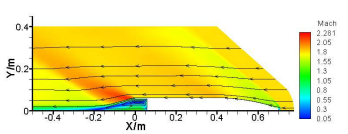

b. base cavity length $6 \mathrm{~cm}$ 


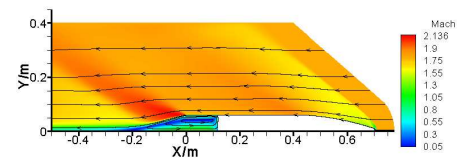

c. base cavity length $12 \mathrm{~cm}$

FIGURE II. MA (STREAMLINES) DISTRIBUTIONS

The distributions of the temperature of the projectile with different cavity length are shown in Fig. 3. As shown in Fig.3, There is a high temperature area behind the projectile and the maximum of the temperature is appeared in this region.

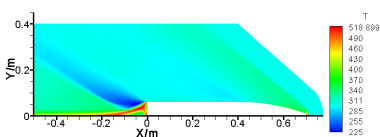

a. projectile without base cavity

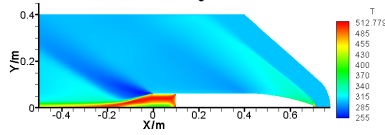

c. base cavity length $12 \mathrm{~cm}$

FIGURE III.

TEMPERATURE DISTRIBUTIONS

The distributions of the pressure of the projectile with different cavity length are shown in Fig. 4. The low speed refluence cause to a partial high pressure area formed behind the projectile. The partial high pressure area increases the base pressure of the projectile, in another side, the base drag of the projectile is reduced.

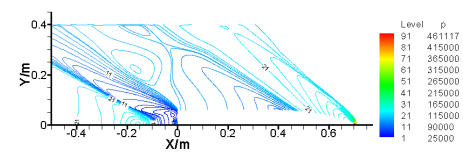

a. projectile without base cavity

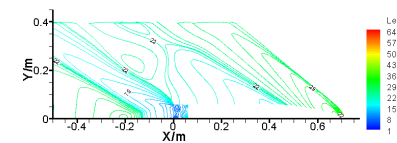

b. base cavity length $6 \mathrm{~cm}$

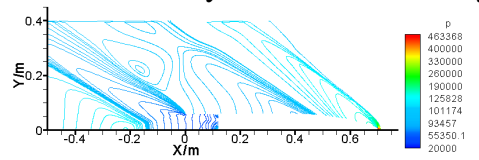

c. base cavity length $12 \mathrm{~cm}$

FIGURE IV.

PRESSURE DISTRIBUTIONS

\section{B. Aerodynamic Drag}

The drag coefficient $(\mathrm{Cd})$ is given by the expression:

$$
C_{d}=F_{d} /\left(\frac{1}{2} \rho_{\infty} u_{\infty}^{2} \cdot S_{r e f}\right)
$$

where $\mathrm{Fd}$ is the aerodynamic resistance, Sref is the reference area which is the cross section of projectile.

The drag coefficient $\left(C_{d}\right)$ of the projectile with different base cavity is shown in Table 1 . With the increasing of the cavity length, the drag of the projectile is reducing. It is obvious that the recirculation region plays a key role for the reduction of the drag. With the length of the base cavity increasing, the velocity of the circumfluence is decreasing and the pressure is increasing, then, the base drag is reduced.

TABLE II DRAG COEFFICIENT (CD).

\begin{tabular}{|c|l|l|l|}
\hline Cavity length (cm) & 0 & 6 & 12 \\
\hline $\boldsymbol{C}_{\boldsymbol{d}}$ & 0.3916 & 0.3333 & 0.3235 \\
\hline
\end{tabular}

\section{CONCLUSIONS}

(1) The base cavity configuration is an effective choice to reduce the aerodynamic drag of the projectile.

(2) The recirculation region plays a pivotal role for the reduction of the drag.

(3) The projectile with deeper base cavity has smaller aerodynamic drag.

\section{REFERENCE}

[1] Wang Z.Y., The effect about projectile of base cavity with side holes to flight drag under supersonic flow. ACTA Aerodynamic Sinica, 15(4), pp. 502-506, 1997.

[2] Wei H.Z \& Zhu H.S., (eds). The design theory of projectile, National Defense Industry Press: Beijing, 1985 (in Chinese)

[3] Wu X.S., The numerical investigation on flow field of projectile (with base bleed). Journal of ballistics, 4(3), pp. 107-110, 1992.

[4] Tao W.Q., Numerical Heat Transfer, 2nd edn. Xi' an Jiaotong University Press: $\quad \mathrm{Xi}^{\prime} \quad$ an, 2001 (in 